\title{
Diagnostic Performance of Retinopathy in the Detection of Diabetic Nephropathy in Type 2 Diabetes: A Systematic Review and Meta-Analysis of 45 Studies
}

\author{
Shimin Jiang ${ }^{a, b}$ Tianyu $\mathrm{Yu}^{\mathrm{a}, \mathrm{b}}$ Zheng Zhang ${ }^{\mathrm{a}, \mathrm{b}}$ Yining Wang ${ }^{\mathrm{c}}$ Jinying Fang ${ }^{\mathrm{d}}$ \\ Yue Yang ${ }^{a}$ Lin Liu ${ }^{a}$ Wenge Lia,b \\ a Department of Nephrology, China-Japan Friendship Hospital, Beijing, China; ${ }^{b}$ Peking Union Medical College and \\ Chinese Academy of Medical Sciences, Beijing, China; 'Peking University Health Science Center, Beijing, China; \\ ${ }^{\mathrm{d}}$ Beijing University of Chinese Medicine, Beijing, China
}

\section{Keywords}

Diabetic retinopathy . Diabetic nephropathy · Diagnosis .

Type 2 diabetes $\cdot$ Meta-analysis

\begin{abstract}
Aims: To conduct an evidence-based evaluation of diabetic retinopathy (DR) for the diagnosis of diabetic nephropathy (DN) in type 2 diabetics with kidney disease. Methods: We systematically searched PubMed, EMBASE, and the Cochrane Library from inception to June 27, 2018, including the reference lists of identified primary studies. A study was included if it (1) used DR as a diagnostic test for DN; and (2) used histological evaluation of renal tissues as the reference standard. Results: The analysis included 45 studies $(4,561$ patients). A bivariate analysis yielded a sensitivity of $0.67(95 \%$ $\mathrm{Cl} 0.61-0.74)$ and a specificity of 0.78 (95\% Cl $0.73-0.82)$. The summary receiver operating characteristic curve analysis provided an area under the curve (AUC) of $0.79(95 \% \mathrm{Cl}$ $0.76-0.83$ ). In a setting of $41 \%$ prevalence of $\mathrm{DN}$, the probability of DN would be $68 \%$ if the test of DR was positive, and the probability of DN would be $23 \%$ if it was negative. In addition, although the mean specificity of proliferative DR for the detection of DN was $0.99(95 \% \mathrm{Cl} 0.45-1.00)$, the mean
\end{abstract}

() 2019 S. Karger AG, Basel sensitivity was $0.34(95 \% \mathrm{Cl} 0.24-0.44)$, and the AUC was 0.58 ( $95 \% \mathrm{Cl} 0.53-0.62)$. Conclusions: DR is helpful in diagnosing DN in persons with type 2 diabetes and kidney disease, but the severity of DR may not parallel the presence of DN.

(c) 2019 S. Karger AG, Base

\section{Introduction}

Over the past few decades, the prevalence of diabetes has increased enormously in both developing and developed countries, with most patients having type 2 diabetes [1]. Thus, the prevalence of microvascular and macrovascular complications associated with diabetes is increasing at alarming rates worldwide [2]. Microvascular changes within the kidney often lead to chronic kidney disease, an entity referred to as diabetic nephropathy (DN) [3].

Patients who present with diabetes and kidney disease can have pure $\mathrm{DN}$, nondiabetic renal disease (NDRD), or mixed forms (DN + NDRD). In clinical practice, diabetic patients with kidney disease usually do not undergo a renal biopsy unless there is a suspicion of NDRD that warrants immunotherapy. Practicing clinicians should therefore make a diagnosis using a thorough history, physical

\section{KARGER}

E-Mail karger@karger.com

www.karger.com/ore
Wenge $\mathrm{Li}, \mathrm{PhD}$, MD

Department of Nephrology, China-Japan Friendship Hospital

No. 2 East Yinghuayuan Street

Chaoyang District, Beijing 100029 (China)

E-Mail wenge_lee2002@126.com 
examination, and laboratory and imaging tests before a biopsy is performed.

Diabetic retinopathy (DR) is the most common microvascular complication of diabetes [4]. Many studies have shown that DR may be helpful in distinguishing DN from NDRD. However, conclusions concerning the diagnostic performance of DR show disagreements between individual studies. Accordingly, one meta-analysis from 2012 investigated the accuracy of DR for the diagnosis of DN [5], but it was limited by the choice of a gold standard for identifying DN and NDRD, and it did not evaluate the clinical utility of DR. In addition, meta-regression and sensitivity analyses were not conducted to explain the reliability of the results. Additionally, new studies dealing with the role of DR in the differential diagnosis of DN and NDRD have been reported since the publication of the previous meta-analysis, so our understanding of DR is still developing.

To overcome these issues and to provide an evidencebased evaluation of the clinical utility of DR, we performed a comprehensive meta-analysis of all published studies comparing DR using histopathological examination in the diagnosis of $\mathrm{DN}$.

\section{Materials and Methods}

This meta-analysis was performed in accordance with the recommendations of the preferred reporting items for systematic reviews and meta-analyses statement [6], and the guidelines for diagnostic meta-analyses [7]. Protocol and registration information are available at PROSPERO (http://www.crd.york.ac.uk/PROSPERO) under registration number CRD42018105799.

Data Sources and Searches

We systematically searched PubMed, EMBASE, and the Cochrane Central Register of Controlled Trials for relevant studies without a time restriction up to June 27, 2018. The search terms included "diabetic retinopathy," AND "diabetic nephropathies," AND "biopsy" OR "pathology." Additional relevant searches were performed by manually searching the references of eligible studies or relevant reviews.

\section{Study Selection}

We included a study if (1) it investigated patients with type 2 diabetes; (2) it assessed the accuracy of DR for differentiation between patients with DN and those with NDRD; (3) it conducted pathological evaluations of renal biopsy specimens (at least routinely processed by light microscopy and immunofluorescence staining) for confirming DN and NDRD; and (4) it reported cases in absolute numbers of true positive, false positive, true negative, and false negative results or stated data to adequately derive this information. Based on renal pathology, patients were divided into 2 groups: (I) the DN group (case), and (II) the NDRD group (control). The biopsy characteristics of mixed and isolated NDRD were categorized as
NDRD. We only included reports published in English or Chinese. DR was defined as the presence of background changes (microaneurysms, hemorrhages, soft exudates, and hard exudates) with or without proliferative DR (PDR) according to well-validated scales, including customized standards, a modification of the Airlie House Classification Scheme [8], or a national grading system [9]. Animal experiments, reviews, correspondences, case reports, expert opinions, and editorials were excluded. Meeting abstracts providing insufficient information regarding their data were also excluded.

\section{Data Extraction and Quality Assessment}

Two investigators independently performed data extraction. When more than 1 publication on a study existed, the reports were grouped together and the publication with the most complete data was included. Inconsistencies were resolved by discussion and consensus. Study quality and applicability were assessed by a revised checklist based on the quality assessment of diagnostic accuracy studies tool-2 [10] by 2 independent investigators, with discrepancies resolved by consensus. This tool consisted of 4 key domains (patient selection, index test, reference standard, and flow and timing), and provided a maximum score of 7 to appraise the quality of the diagnostic studies. Each domain was assessed in terms of the bias risk, and the first 3 domains were also assessed in terms of concerns regarding applicability.

We contacted the corresponding authors of 4 studies [11-14] that met the inclusion criteria but did not provide specific data on the methods of pathological examination of biopsy specimens. If no response was received after sending a reminder, the study was excluded.

\section{Data Synthesis and Statistical Analysis}

Categorical variables from the studies are presented as percentages and continuous variables as mean values. We applied an exact binomial rendition [15] of the bivariate mixed-effects regression model to synthesize data, which was developed by van Houwelingen $[16,17]$ for the meta-analysis of treatment trials, and modified for the synthesis of diagnostic test data $[18,19]$. Based on this model, we calculated sensitivity, specificity, and positive and negative likelihood ratios (PLR and NLR, respectively). We then used the derived logit estimates of sensitivity, specificity, and respective variances to construct a summary receiver operating characteristic (SROC) curve. The area under the SROC curve (AUC) represented an analytical conclusion of the diagnostic performance of DR. An AUC of 1.0 indicated perfect discriminatory ability to distinguish DN from NDRD. Heterogeneity was assessed by the Q-statistic and $I^{2}$ index. Significant heterogeneity was defined as a Qstatistic $p<0.10$ and/or $I^{2}>50 \%$. Subgroup and meta-regression analyses were performed according to the characteristics of the included studies to explore the potential sources of interstudy heterogeneity. Publication bias was assessed by using the Deeks' funnel test [19], with a value of $p<0.05$ for a slope coefficient indicative of publication bias.

We also examined the clinical utility of DR using Bayes' theorem [20], where pretest probability $=$ prevalence of target condition, and post-test probability $=\mathrm{LR} \times$ pretest probability $/([1-$ pretest probability $] \times[1-\mathrm{LR}])$. Assuming that the study samples were representative of the entire population, an estimate of the pretest probability of DN was calculated from the global prevalence of this disorder across studies. Statistical analyses were performed using STATA version 12.0 (STATA, Lakeway Drive, College Station, TX, USA). 
Fig. 1. Flow diagram of article selection. DN, diabetic nephropathy; NDRD, nondiabetic renal disease.

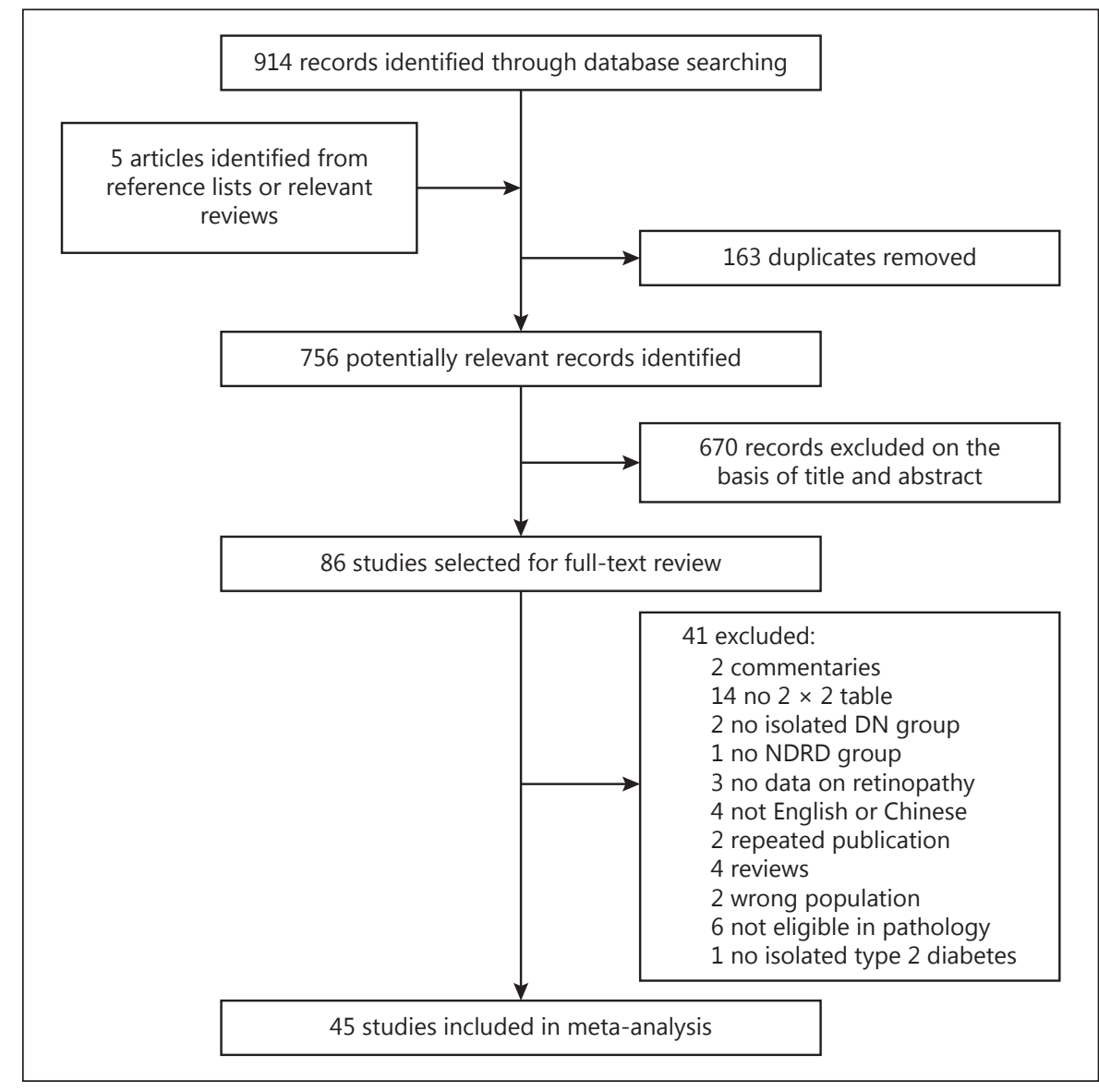

\section{Results}

\section{Literature Search Results}

We retrieved 914 articles from a database search and 5 additional studies by exploring additional sources. After the removal of duplicates, 756 articles were screened based on the title and abstract. The remaining 86 articles were assessed in full text for eligibility. Of 86 reports, 45 were deemed eligible based on the predefined study eligibility criteria. The literature-screening process is summarized in Figure 1.

\section{Study Characteristics}

Table 1 summarizes the characteristics of the included studies. The 45 studies included a total of 4,561 patients with type 2 diabetes and kidney disease. Of the 45 studies, biopsy specimens were routinely processed by light microscopy, immunofluorescence, and electron microscopy in 31 studies [12, 21-50]. In 2 studies [51, 52], immunofluorescence was performed in most cases, and electron microscopy was selectively performed. In the remaining
12 studies [13, 14, 53-62], biopsy specimens were routinely processed by light and immunofluorescence microscopy. The publication years ranged from 1992 to 2018. The number of subjects enrolled in each study ranged from 15 [49] to 328 [44]. In total, 13 studies had a prospective design $[21,22,24,26,27,31,36,40,48,53$, $56,57,62]$ and 32 had a retrospective design [12-14, 23, $25,28-30,32-35,37-39,41-47,49-52,54,55,58-61]$. Of 29 articles $[12-14,28-37,40,43,44,46-50,52-56,58,60$, 62] focusing on Asian populations, 22 [12-14, 28-37, 43, $44,46-50,52,58]$ were performed in East Asian countries. Fourteen articles [21-27, 38, 39, 41, 42, 51, 57, 59] were performed in Europe and America, one in an Oceanic nation [45], and one in an African region [61].

Different methods were used to evaluate DR: ophthalmoscopy after mydriasis in 7 studies $[14,21,22,24,34$, $48,50]$; ophthalmoscopy without mydriasis in 12 studies $[12,26,28,36,38,43,47,49,52,57,60,62]$; fluorescein angiography in 2 studies [25, 27]; ophthalmoscopy/fundoscopy and fluorescein angiography in 6 studies [30, 32, $33,35,40,61]$; and, in 18 cases, no relevant details were 
Table 1. Characteristics of included studies

\begin{tabular}{|c|c|c|c|c|c|c|c|c|c|c|c|c|c|}
\hline Author, year & Region & Design & $\begin{array}{l}\text { Patients } \\
\text { (n) }\end{array}$ & $\begin{array}{l}\text { Men } \\
(\%)\end{array}$ & Age, years & DR evaluation & Selection & $\mathrm{TP}$ & FP & FN & $\mathrm{TN}$ & SEN & SPE \\
\hline $\begin{array}{l}\text { Parving } \\
{[21], 1992}\end{array}$ & Denmark & Prospective & 35 & 94.3 & $55.23 \pm 8.68$ & $\begin{array}{l}\text { Ophthalmoscopy } \\
\text { and fundus photography } \\
\text { after mydriasis }\end{array}$ & $\begin{array}{l}\text { Macroalbuminuria } \\
\text { (UAE } \geq 0.3 \text { g/day) }\end{array}$ & 16 & 0 & 11 & 8 & 0.59 & 1 \\
\hline $\begin{array}{l}\text { John } \\
{[62], 1994}\end{array}$ & Indian & Prospective & 74 & NA & NA & Ophthalmoscopy & Suspected NDRD & 6 & 7 & 8 & 53 & 0.43 & 0.88 \\
\hline $\begin{array}{l}\text { Fioretto } \\
{[22], 1996}\end{array}$ & Italy & Prospective & 34 & 76.5 & $58.5 \pm 7.3$ & $\begin{array}{l}\text { Ophthalmoscopy } \\
\text { after mydriasis }\end{array}$ & $\begin{array}{l}\text { Microalbuminuria } \\
\text { (AER 20-200 } \mu \mathrm{g} / \mathrm{min} \text { ) }\end{array}$ & 10 & 13 & 0 & 11 & 1 & 0.46 \\
\hline $\begin{array}{l}\text { Olsen } \\
{[23], 1996}\end{array}$ & Denmark & Retrospective & 32 & NA & $62.16 \pm 8.29$ & NA & Suspected NDRD & 19 & 1 & 10 & 2 & 0.66 & 0.67 \\
\hline $\begin{array}{l}\text { Brocco } \\
{[24], 1997}\end{array}$ & Italy & Prospective & 53 & 66.04 & $57.72 \pm 3.24$ & $\begin{array}{l}\text { Ophthalmoscopy } \\
\text { after mydriasis }\end{array}$ & $\begin{array}{l}\text { Microalbuminuria } \\
\text { (AER 20-200 } \mu \mathrm{g} / \mathrm{min} \text { ) }\end{array}$ & 14 & 15 & 0 & 24 & 1 & 0.62 \\
\hline $\begin{array}{l}\text { Mak } \\
{[48], 1997}\end{array}$ & China & Prospective & 51 & 70.6 & $54.67 \pm 4.12$ & $\begin{array}{l}\text { Ophthalmoscopy } \\
\text { after mydriasis }\end{array}$ & $\begin{array}{l}\text { Proteinuria } \\
(>1 \text { g/day })\end{array}$ & 20 & 10 & 14 & 7 & 0.59 & 0.41 \\
\hline $\begin{array}{l}\text { Lee } \\
{[49], 1999}\end{array}$ & Korea & Retrospective & 15 & NA & NA & Ophthalmoscopy & Suspected NDRD & 5 & 1 & 2 & 7 & 0.71 & 0.88 \\
\hline $\begin{array}{l}\text { Christensen } \\
{[26], 2000}\end{array}$ & Denmark & Prospective & 34 & 94.1 & $52.47 \pm 2.38$ & $\begin{array}{l}\text { Direct } \\
\text { ophthalmoscopy }\end{array}$ & $\begin{array}{l}\text { Macroalbuminuria } \\
\text { (UAE } \geq 0.3 \mathrm{~g} / \text { day) }\end{array}$ & 17 & 0 & 9 & 8 & 0.65 & 1.00 \\
\hline $\begin{array}{l}\text { Nzerue } \\
{[25], 2000}\end{array}$ & USA & Retrospective & 31 & 48.4 & $49.59 \pm 9.68$ & $\begin{array}{l}\text { Fluorescein } \\
\text { angiography }\end{array}$ & Suspected NDRD & 9 & 6 & 4 & 12 & 0.69 & 0.67 \\
\hline $\begin{array}{l}\text { Serra } \\
{[27], 2002}\end{array}$ & Spain & Prospective & 35 & NA & NA & $\begin{array}{l}\text { Fluorescein } \\
\text { angiography }\end{array}$ & Suspected NDRD & 9 & 3 & 17 & 6 & 0.35 & 0.67 \\
\hline $\begin{array}{l}\text { Wong } \\
{[28], 2002}\end{array}$ & China & Retrospective & 68 & 55.9 & $48.66 \pm 13.29$ & Ophthalmoscopy & Suspected NDRD & 17 & 14 & 7 & 30 & 0.71 & 0.68 \\
\hline $\begin{array}{l}\mathrm{Li} \\
{[29], 2003}\end{array}$ & China & Retrospective & 29 & 75.9 & NA & NA & Suspected NDRD & 2 & 5 & 5 & 17 & 0.29 & 0.77 \\
\hline $\begin{array}{l}\text { Moger } \\
{[53], 2005}\end{array}$ & India & Prospective & 26 & 80.77 & $46.8 \pm 10.3$ & NA & Suspected NDRD & 9 & 11 & 0 & 6 & 1 & 0.35 \\
\hline $\begin{array}{l}\text { Tone } \\
{[30], 2005}\end{array}$ & Japan & Retrospective & 81 & NA & NA & $\begin{array}{l}\text { Direct ophthalmoscopy } \\
\text { and fluorescein } \\
\text { angiography }\end{array}$ & Suspected NDRD & 20 & 4 & 3 & 54 & 0.87 & 0.93 \\
\hline $\begin{array}{l}\text { Soni } \\
{[54], 2006}\end{array}$ & India & Retrospective & 160 & 73.75 & $51.35 \pm 9.64$ & NA & Suspected NDRD & 34 & 65 & 10 & 51 & 0.77 & 0.44 \\
\hline $\begin{array}{l}\text { Pham } \\
{[51], 2007}\end{array}$ & USA & Retrospective & 233 & 53 & $58.1 \pm 13.7$ & NA & Suspected NDRD & 21 & 20 & 43 & 149 & 0.33 & 0.88 \\
\hline $\begin{array}{l}\text { Akimoto } \\
{[50], 2008}\end{array}$ & Japan & Retrospective & 50 & 58 & $52.96 \pm 11.38$ & $\begin{array}{l}\text { Direct ophthalmoscopy } \\
\text { after mydriasis }\end{array}$ & Suspected NDRD & 21 & 7 & 13 & 9 & 0.62 & 0.56 \\
\hline $\begin{array}{l}\text { Zhou } \\
{[31], 2008}\end{array}$ & China & Prospective & 110 & 69.7 & $46.3 \pm 11.8$ & NA & $\begin{array}{l}\text { Proteinuria } \\
(\mathrm{UPE} \geq 0.5 \mathrm{~g} / \mathrm{d})\end{array}$ & 46 & 5 & 14 & 45 & 0.77 & 0.90 \\
\hline $\begin{array}{l}\text { Lin } \\
{[32], 2009}\end{array}$ & China & Retrospective & 50 & 64 & $61.55 \pm 12.59$ & $\begin{array}{l}\text { Ophthalmoscopy } \\
\text { after mydriasis and } \\
\text { fluorescein angiography }\end{array}$ & Suspected NDRD & 12 & 12 & 12 & 14 & 0.50 & 0.54 \\
\hline $\begin{array}{l}\text { Mou } \\
{[12], 2010}\end{array}$ & China & Retrospective & 69 & 52.2 & $53.07 \pm 7.48$ & Ophthalmoscopy & $\begin{array}{l}\text { Proteinuria } \\
(>1 \text { g/day })\end{array}$ & 25 & 4 & 8 & 32 & 0.76 & 0.89 \\
\hline $\begin{array}{l}\mathrm{Bi} \\
{[52], 2011}\end{array}$ & China & Retrospective & 220 & 69.54 & $50.84 \pm 11.69$ & Ophthalmoscopy & Suspected NDRD & 92 & 10 & 28 & 90 & 0.77 & 0.90 \\
\hline $\begin{array}{l}\text { Chang } \\
{[33], 2011}\end{array}$ & Korea & Retrospective & 119 & 53.78 & $53.03 \pm 10.73$ & $\begin{array}{l}\text { Direct } \\
\text { ophthalmoscopy and } \\
\text { fluorescein angiography }\end{array}$ & Suspected NDRD & 34 & 17 & 9 & 59 & 0.79 & 0.78 \\
\hline $\begin{array}{l}\text { Chong } \\
{[55], 2012}\end{array}$ & Malaysia & Retrospective & 89 & NA & NA & NA & Suspected NDRD & 50 & 17 & 5 & 17 & 0.91 & 0.50 \\
\hline $\begin{array}{l}\text { Oh [34], } \\
2012\end{array}$ & Korea & Retrospective & 126 & 68.25 & $59.9 \pm 10.8$ & $\begin{array}{l}\text { Ophthalmoscopy } \\
\text { after mydriasis }\end{array}$ & Suspected NDRD & 39 & 15 & 11 & 61 & 0.78 & 0.80 \\
\hline $\begin{array}{l}\text { Byun } \\
{[35], 2013}\end{array}$ & Korea & Retrospective & 110 & 61.82 & $52.66 \pm 11.8$ & $\begin{array}{l}\text { Fundoscopy and } \\
\text { fluorescein angiography }\end{array}$ & Suspected NDRD & 31 & 13 & 10 & 56 & 0.76 & 0.81 \\
\hline
\end{tabular}


Table 1. (continued)

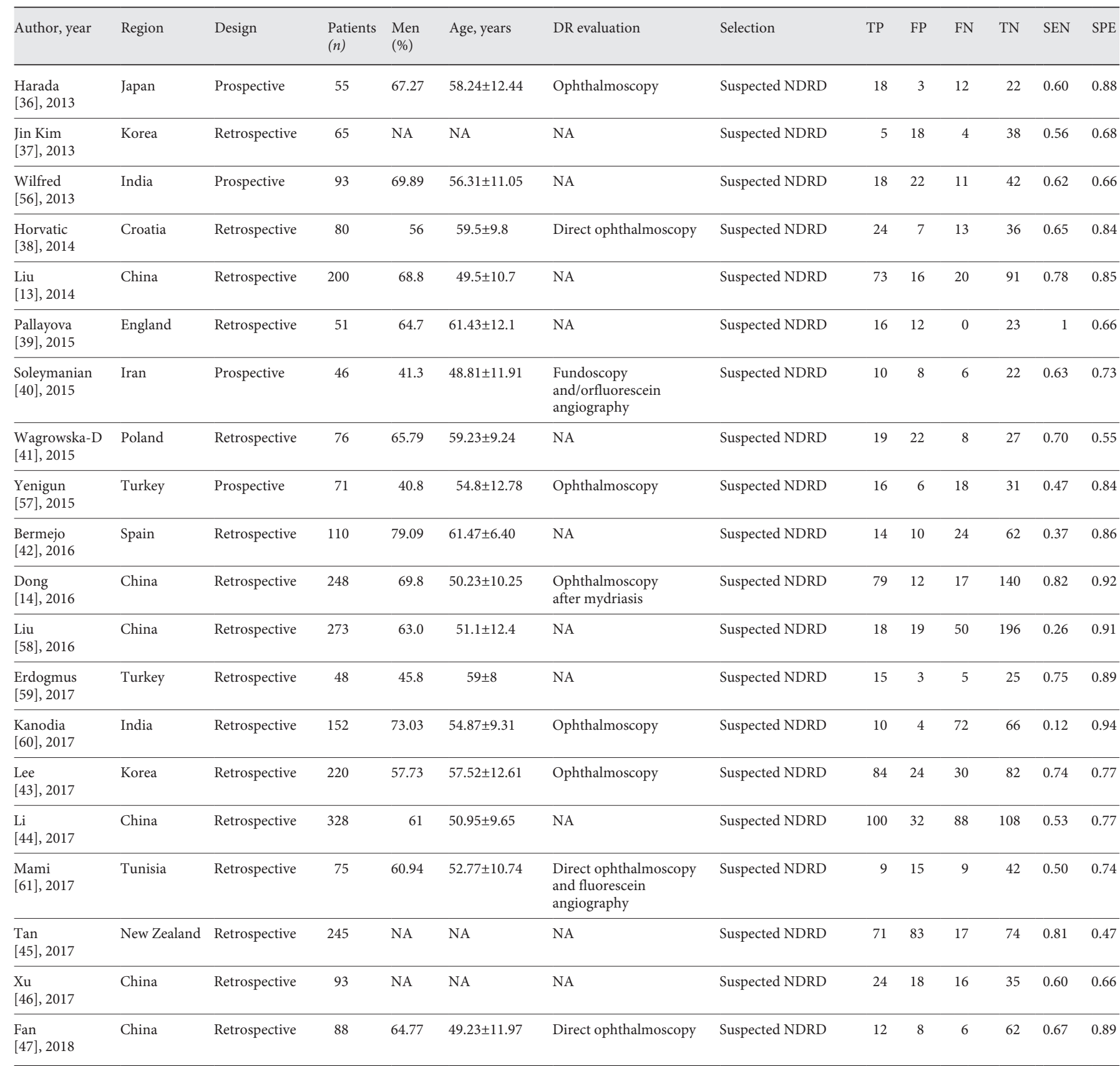

UAE, urinary albumin excretion; AER, albumin excretion ratio; UPE, urinary protein excretion; NA, not available; DR, diabetic retinopathy; TP, true positive; FP, false positive; TN, true negative; FN, false negative; SEN, sensitivity; SPE, specificity; NDRD, non-diabetic renal disease.

provided $[13,23,29,31,37,39,41,42,44-46,51,53-56$, 58, 59].

The indications for renal biopsy in patients with type 2 diabetes were extremely variable across the studies. Seven studies reported data from renal biopsies because of varying degrees of proteinuria [12, 21, 22, 24, 26, 31, 48].
In the remaining 38 studies, the major driver was the clinical suspicion of NDRD, including the absence of DR, abrupt increases in serum creatinine or proteinuria, rapid worsening of renal function, unexplained microscopic hematuria, and renal failure in patients without macroalbuminuria. 


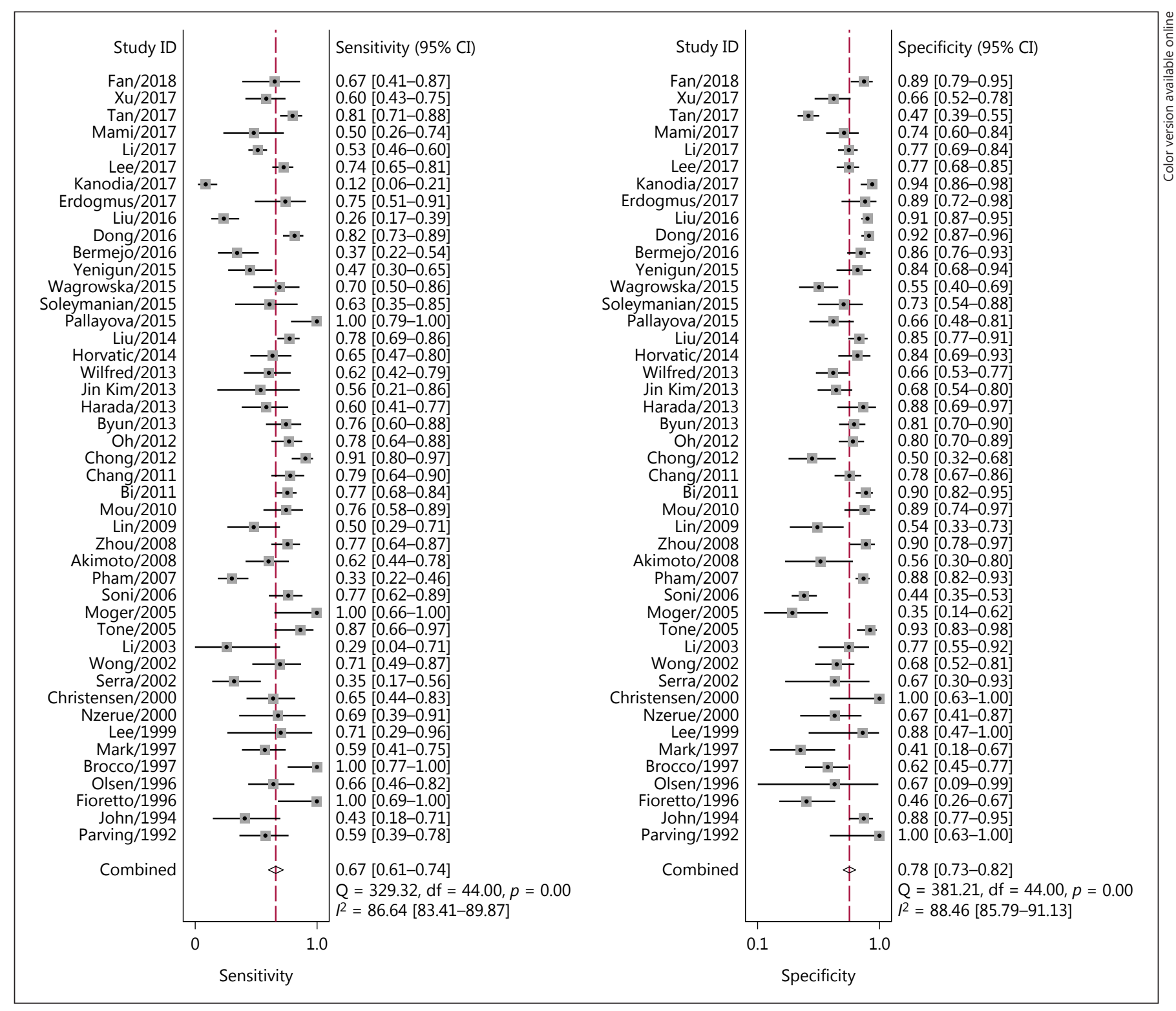

Fig. 2. Sensitivity and specificity of DR for the diagnosis of DN.

\section{Quality Assessments}

Quality assessments and the scores of the included studies according to the Quality Assessment of Diagnostic Accuracy Studies Tool-2 are shown in online supplementary Table 1 (for all online suppl. material, see www. karger.com/doi/10.1159/000500833). For each domain, the risk of bias and concerns about applicability were analyzed and rated as low, high, or unclear risk. The vast majority of the studies were ranked as a moderately high quality for most of the domains.

\section{The Use of DR to Predict DN}

\section{Summary Performance Estimates}

Forest plots of data from the 45 studies involving the sensitivity and specificity of DR in diagnosing DN are shown in Figure 2. Because significant heterogeneity between studies was observed in sensitivity $\left(I^{2}=86.64\right.$; $p<0.01)$ and specificity $\left(I^{2}=88.46 ; p<0.01\right)$, the randomeffects model was used to appraise the diagnostic accuracy of DR for DN. After pooling 45 datasets (4,561 patients), DR showed a sensitivity of 0.67 (95\% CI $0.61-0.74)$ and specificity of 0.78 (95\% CI 0.73-0.82). The pooled AUC of 


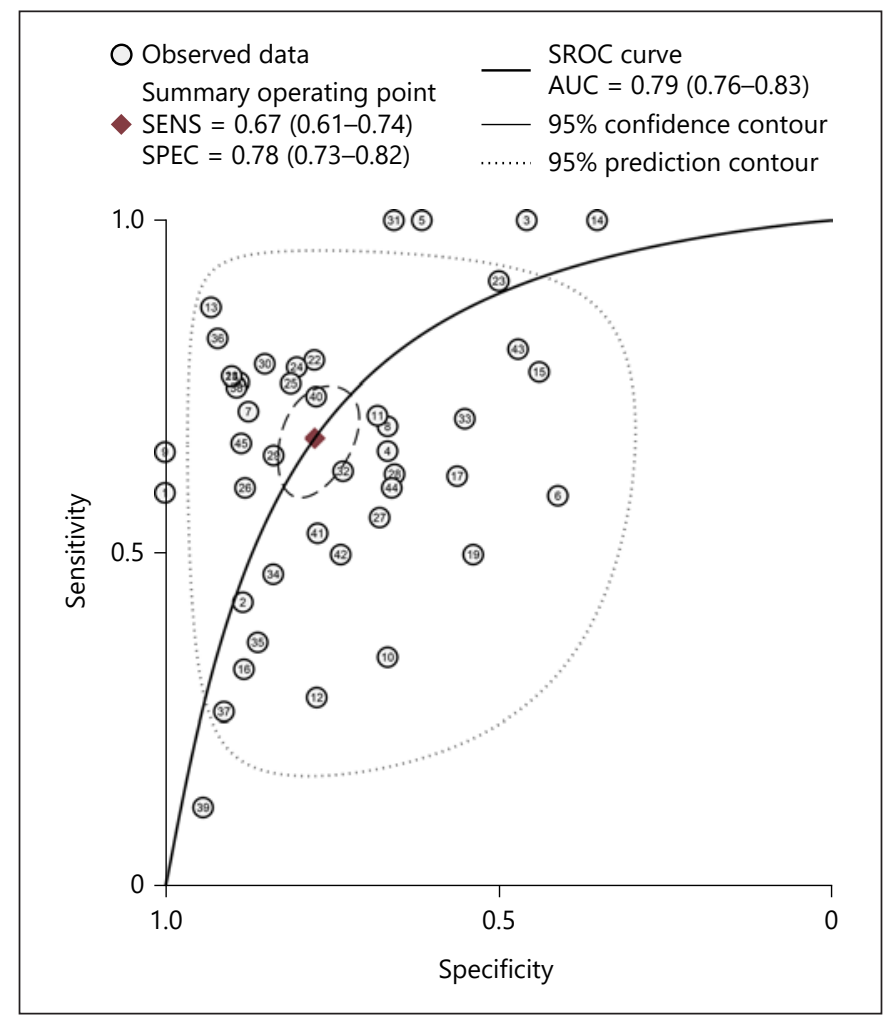

Fig. 3. SROC curve with pooled estimates of AUC. AUC, area under the curve; SROC, summary receiver operating characteristic; SENS, sensitivity; SPEC, specificity.

the SROC curve was 0.79 (95\% CI 0.76-0.83), representing moderately good discrimination (Fig. 3). The prevalence of NDRD in this group was 58.5\% (2,669 of 4,561).

Subgroup Analysis

A subgroup analysis based on ethnicity (East Asians vs. Caucasians) was conducted to identify whether ethnic differences affected the diagnostic accuracy. The sensitivity and specificity for Asians were 0.68 and 0.81 , respectively, while for Caucasians they were 0.67 and 0.75 , respectively. In a similar manner, the AUC for Asians was 0.81 , which is higher than that for Caucasians (AUC of 0.78 ). Overall, the results show that the accuracy of DR in predicting DN for Asians was slightly higher than for Caucasians.

\section{Meta-Regression and Robustness Tests}

A meta-regression analysis was performed to further investigate the potential sources of interstudy heterogeneity, and to confirm the results of the subgroup analysis (Fig. 4). The results indicate that sample size and study design (pro-

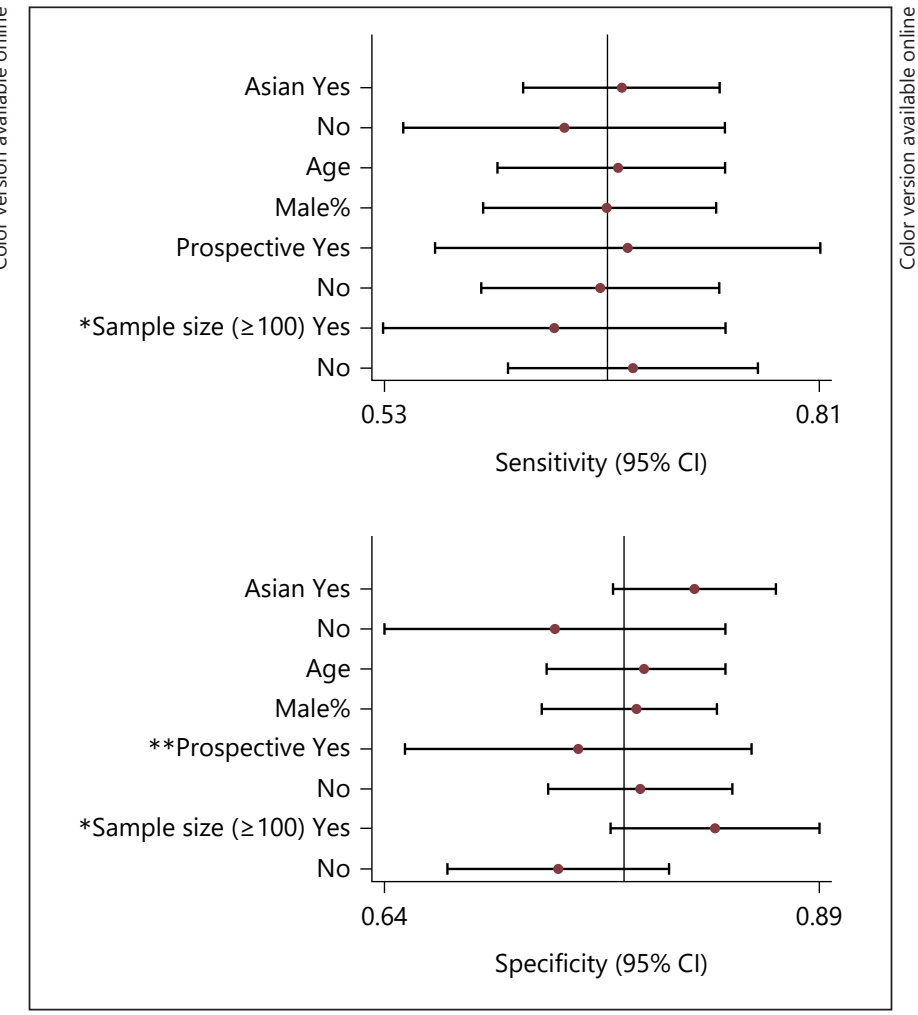

Fig. 4. Univariate meta-regression and subgroup analyses on ethnicity, age, male to female ratio, study design and sample size for sensitivity and specificity. Factors with asterisk are potential sources of heterogeneity. ${ }^{*} p<0.05,{ }^{* *} p<0.01$.

spective or retrospective) might be the major sources of heterogeneity ( $p<0.05$ and $p<0.01$, respectively; Fig. 4 ). Goodness-of-fit and bivariate normality analyses (Fig. 5a, b) showed that the bivariate model was robust. An influence analysis and outlier detection identified 5 outliers (Fig. 5c, d). After we excluded these outliers and conducted the same analyses for the remaining studies, we found that the overall results did not change significantly (Table 2).

Evaluating Clinical Utility

The PLR of DR for diagnosing DN was 3.01 (95\% CI $2.47-3.66)$, and the NLR was 0.42 (95\% CI $0.35-0.51)$. Using the rule of thumb that for a diagnostic test to be useful it should have a high PLR ( $>5$; i.e., good at ruling in a disease) and a low NLR $(<0.2$; i.e., good at eliminating a disease), DR as a single index test was not good at confirming and excluding DN. Figure 6 shows the Fagan nomogram of DR for the diagnosis of DN. Given a pretest probability of $41 \%$, the post-test probability for a positive result was $68 \%$. Likewise, an NLR of 0.42 reduced the post-test probability to $23 \%$ for a negative test result. 


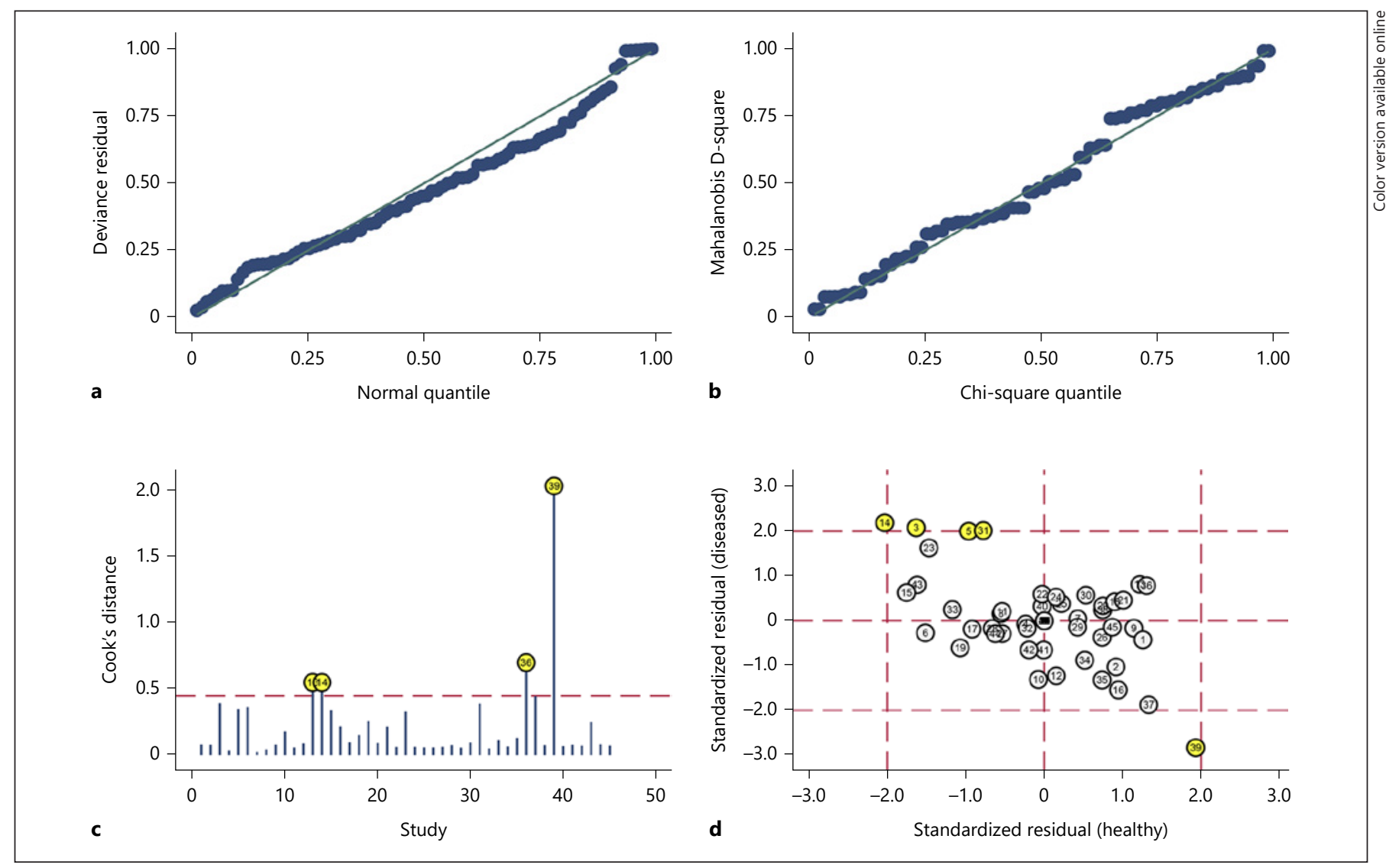

Fig. 5. Graphs for sensitivity analyses: (a) goodness-of-fit, (b) bivariate normality, (c) influence analysis, and (d) outlier detection.

Table 2. Diagnostic performance of DR and subgroup analysis based on ethnicity

\begin{tabular}{lcrrr}
\hline & Overall & Outliers excluded & East Asians & Caucasians \\
\hline Number of studies, $n$ & 45 & 40 & 22 & 12 \\
Number of patients, $n$ & 4,561 & 4,245 & 2,678 & 619 \\
SEN (95\% CI) & $0.67(0.61-0.74)$ & $0.65(0.60-0.70)$ & $0.68(0.61-0.74)$ & $0.67(0.55-0.77)$ \\
SPE (95\% CI) & $0.78(0.73-0.82)$ & $0.79(0.74-0.84)$ & $0.81(0.76-0.86)$ & $0.75(0.66-0.83)$ \\
AUC (95\% CI) & $0.79(0.76-0.83)$ & $0.78(0.74-0.82)$ & $0.81(0.78-0.84)$ & $0.78(0.74-0.81)$ \\
\hline
\end{tabular}

DR, diabetic retinopathy; SEN, sensitivity; SPE, specificity; AUC, area under the summary receiver operating characteristic curve.

The Use of PDR to Predict DN

Of the 45 studies, 15 [21-24, 26, 28, 32, 34-36, 40, 48$50,57]$ delineated the classification of DR severity (none, background DR, and PDR). But data regarding PDR could be obtained only from 6 studies [21-24, 26, 34]. After pooling the 6 datasets ( 314 patients), PDR showed a sensitivity of 0.34 (95\% CI 0.240 .44$)$ and specificity of 0.99 (95\% CI 0.45-1.00) for diagnosis of DN. The SROC curve showed an AUC of 0.58 (95\% CI 0.53-0.62). There was moderate heterogeneity in the sensitivity $\left(I^{2}=57.0 \%\right.$; $p<0.01)$, but no heterogeneity in specificity $\left(I^{2}=1.83 \%\right.$; $p<0.01$ ) between studies.

\section{Publication Bias}

The Deeks' funnel plot asymmetry test was conducted to assess the potential publication bias. The slope coefficient was associated with a $p$ value of 0.72 in the overall studies (Fig. 7a), and a $p$ value of 0.80 in 


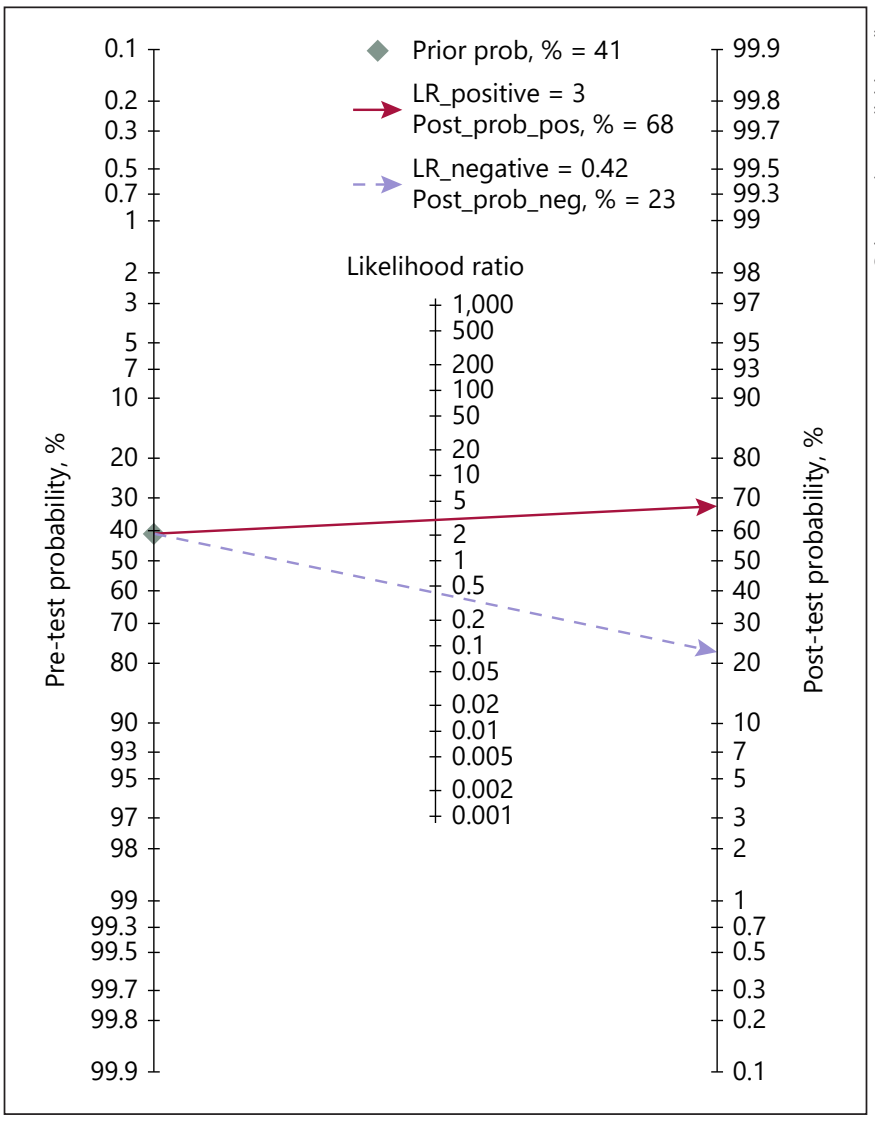

Fig. 6. Fagan's nomogram for DR shows post-test probability of $\mathrm{DN}$ in type 2 diabetes with kidney disease. LR, likelihood ratios.

studies investigating the PDR (Fig. 7b), suggesting symmetry in the data and a low likelihood of publication bias.

\section{Discussion}

The present study examined the diagnostic performance data of DR from multiple centers throughout the world to assess the accuracy and clinical value of DR in the detection of DN in type 2 diabetes. Our results suggest that DR was helpful in differentiating DN from NDRD, although the overall test performance was not as high as expected, and the severity of DR may not parallel the presence of DN.

Previously, one meta-analysis from 2012 [5] investigated the diagnostic accuracy of both DR and PDR in biopsy studies, with different results. However, their findings were heavily biased because of their inclusion criteria. First, their reference tests were imperfect because the investigators also included studies that only performed light microscopy or did not mention how renal specimens were processed. Second, the researchers only investigated a total of 4 studies with 169 patients having PDR (a small sample size), including 1 study analyzing PDR after a mean follow-up of 7 years (not the data at the time of biopsy). This would lead to an inappropriate interval between the index test and the reference standard. Furthermore, the researchers did not perform a subgroup analysis and meta-regression to further explain the reliability of the results. Finally, the investigators did not examine the clinical utility of DR, which is also vital for clinicians in actual clinical practice.

This meta-analysis showed that the pooled sensitivity and specificity of DR for indicating DN in type 2 diabetes were 0.67 and 0.78 , respectively. In addition, the AUC was 0.79 , suggesting DR had a moderately high diagnostic accuracy for the discrimination between DN and NDRD. It is clear that the diagnostic accuracy of DR for the diagnosis of $\mathrm{DN}$ in the present study was higher than that in the meta-analysis from 2012 [5].

Overall, the PLR and NLR are more meaningful indicators of diagnostic accuracy. A PLR above 5 and NLR below 0.2 have been noted as providing strong diagnostic evidence [63]. In this meta-analysis, the pooled PLR and NLR were 3.01 and 0.42 , respectively. As a measure of test performance, the LR has advantages over sensitivity and specificity because it also changes with disease prevalence and can be used to calculate post-test probability. In clinical practice, the LR and post-test probabilities are also relevant for clinicians because they provide information about the likelihood that a patient with a positive or negative DR test actually has DN. Because post-test probability depends on disease prevalence, the practical use of the results relies on the cognizance of DN prevalence at individual medical centers. In our study, both the LR and post-test probabilities were moderate. The clinical utility of DR in diabetes is evident when the test for DR is negative, decreasing the probability of $\mathrm{DN}$ to $23 \%$. A positive test is also useful, when the probability of disease increases to approximately 70\% (Fig. 6).

There are studies reporting that ethnic differences affect susceptibility to the development of DR $[64,65]$. The subgroup analysis and meta-regression in this meta-analysis were therefore conducted to explore potential sources of heterogeneity. According to Table 2, DR as a single index test in the detection of DN for East Asians showed a higher sensitivity and specificity than that for Caucasians. Moreover, the AUC of the SROC curve in the Asian population was 0.81 , which is higher than that in the Cau- 


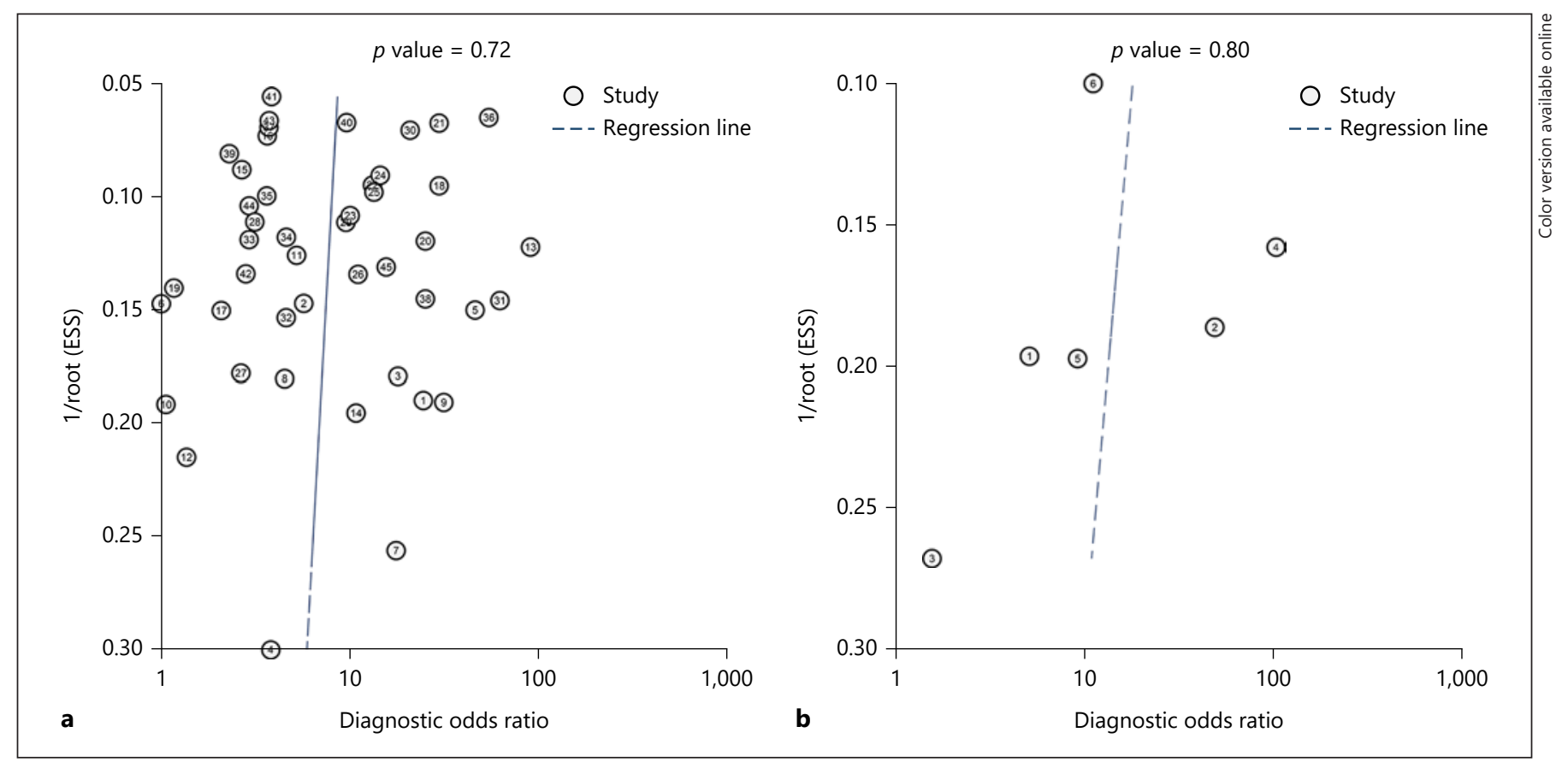

Fig. 7. Graph of Deek's funnel plot asymmetry test. a Studies evaluating DR; (b) studies evaluating PDR.

casian population (0.78). However, meta-regression analysis showed that ethnic origin had no influence on the interstudy heterogeneity. In this study, 12 studies including 619 patients investigated Caucasian populations, which was a very small sample size. Whether DR is a less powerful tool for Caucasian populations in $\mathrm{DN}$ diagnosis compared with Asian populations will require a larger study.

In the meta-analysis from 2012 [5], the data (169 patients) showed that PDR might be a highly specific indicator for DN with an AUC of 0.99, indicating that the test results were highly accurate. However, after pooling 6 datasets (314 patients) in the present study, although PDR still had a very high specificity (0.99), it demonstrated an AUC of 0.58 , representing very low diagnostic performance for the detection of DN. Combined with the overall diagnostic performance of DR, our results show that the severity of DR might not correlate with the presence of DN in individuals with type 2 diabetes, in contrast to a previous meta-analysis [5]. A larger study with a broad spectrum of DR severity is required because there are currently limited data available on the association of DR severity and the presence of biopsy-proven $\mathrm{DN}$.

Our review has several limitations and strengths. First, this study assessed different methods of evaluating $\mathrm{DR}$, and some studies did not provide relevant details.
In addition, the studies included patients with microalbuminuria or macroalbuminuria with ranges defined from $>300 \mathrm{mg} /$ day to nephrotic-range proteinuria, and those with different levels of renal function, or those that were not clearly defined. Third, there were different disease categories of renal pathologies between studies. In most studies, overlapping cases were classified in the NDRD group, whereas 5 studies [13, 14, 29, 31, 39] excluded a pathological diagnosis of NDRD combined with DN. Finally, most of the included studies reported data on the frequency of DR based on a clinical suspicion of NDRD in diabetic patients. These individuals may not be representative of patients with $\mathrm{DN}$ in the general population. The strengths of our study include stricter inclusion criteria and subgroup and meta-regression analyses. An influence analysis and outlier detection were then conducted to evaluate the robustness of the tests. The utility of Bayes' theorem was also a strength of this meta-analysis.

In conclusion, measuring DR was helpful in diagnosing $\mathrm{DN}$ in patients with type 2 diabetes and kidney disease. Although PDR may have very high specificity for the diagnosis of $\mathrm{DN}$, it has much lower diagnostic performance than DR in distinguishing DN from NDRD, indicating that there may be no equivalent relationship between the severity of DR and the presence of $\mathrm{DN}$ in type 
2 diabetes. Nevertheless, better detection of retinopathy, which is noninvasive and inexpensive, may be one way to identify persons with DN more accurately.

\section{Statement of Ethics}

All analyses were based on existing studies in the published literature, and thus, no ethical approval and patient consent are required. Nonetheless, the study adhered fully to the Declaration of Helsinki.

\section{Disclosure Statement}

The authors have no conflict of interest to disclose.

\section{Funding Sources}

This research was funded by Science and Technology Project of Beijing (D171100002817003; D171100002817002), National Key R\&D Program of China (2016YFC1305500), China Health Promotion Foundation (DKD-MBD project, 2018-2022), and National Natural Science Foundation of China (81600547).

\section{Author Contributions}

S.J., T.Y., and Y.W.: extracted data from previous studies and analyzed and interpreted the results. W.L.: provided oversight for the extraction, analysis, and interpretation of the data. S.J.: drafted the manuscript. J.F., Z.Z., L.L., and Y.Y.: ensured that the analysis was conducted appropriately and verified the accuracy of results presented in the manuscript.

\section{References}

$1 \mathrm{Hu}$ FB. Globalization of diabetes: the role of diet, lifestyle, and genes. Diabetes Care. 2011 Jun;34(6):1249-57.

2 Dabelea D, Stafford JM, Mayer-Davis EJ, D’Agostino R Jr, Dolan L, Imperatore G, et al.; SEARCH for Diabetes in Youth Research Group. Association of type 1 diabetes vs type 2 diabetes diagnosed during childhood and adolescence with complications during teenage years and young adulthood. JAMA. 2017 Feb;317(8):825-35.

3 Tervaert TW, Mooyaart AL, Amann K, Cohen AH, Cook HT, Drachenberg CB, et al.; Renal Pathology Society. Pathologic classification of diabetic nephropathy. J Am Soc Nephrol. 2010 Apr;21(4):556-63.

4 Yau JW, Rogers SL, Kawasaki R, Lamoureux EL, Kowalski JW, Bek T, et al.; Meta-Analysis for Eye Disease (META-EYE) Study Group. Global prevalence and major risk factors of diabetic retinopathy. Diabetes Care. 2012 Mar;35(3):556-64.

5 He F, Xia X, Wu XF, Yu XQ, Huang FX. Diabetic retinopathy in predicting diabetic nephropathy in patients with type 2 diabetes and renal disease: a meta-analysis. Diabetologia. 2013 Mar;56(3):457-66.

6 Moher D, Liberati A, Tetzlaff J, Altman DG; PRISMA Group. Preferred reporting items for systematic reviews and meta-analyses: the PRISMA statement. Ann Intern Med. 2009 Aug;151(4):264-9.

7 Leeflang MM, Deeks JJ, Gatsonis C, Bossuyt PM; Cochrane Diagnostic Test Accuracy Working Group. Systematic reviews of diagnostic test accuracy. Ann Intern Med. 2008 Dec;149(12):889-97.

8 Diabetic Retinopathy Study Research Group. Retinopathy 7: A modification of the Airlie House Classification of diabetic retinopathy. Invest Ophthalmol Vis Sci. 1981 Jul;21(1): $210-26$.
9 Wilkinson CP, Ferris FL 3rd, Klein RE, Lee PP, Agardh CD, Davis M, et al.; Global Diabetic Retinopathy Project Group. Proposed international clinical diabetic retinopathy and diabetic macular edema disease severity scales. Ophthalmology. 2003 Sep;110(9): 1677-82.

10 Whiting PF, Rutjes AW, Westwood ME, Mallett S, Deeks JJ, Reitsma JB, et al.; QUADAS-2 Group. QUADAS-2: a revised tool for the quality assessment of diagnostic accuracy studies. Ann Intern Med. 2011 Oct;155(8): 529-36.

11 Chawarnkul O, Vareesangthip K, Ongajyooth L, Cheunsuchon B, Parichatikanond P. Nondiabetic glomerular disease in type II DM: 10 years experience. J Med Assoc Thai. 2009 Mar;92 Suppl 2:S57-60.

12 Mou S, Wang Q, Liu J, Che X, Zhang M, Cao $L$, et al. Prevalence of non-diabetic renal disease in patients with type 2 diabetes. Diabetes Res Clin Pract. 2010 Mar;87(3):354-9.

13 Liu MY, Chen XM, Sun XF, Zhou JH, Zhang $\mathrm{XG}$, Zhu HY, et al. Validation of a differential diagnostic model of diabetic nephropathy and non-diabetic renal diseases and the establishment of a new diagnostic model. J Diabetes. 2014 Nov;6(6):519-26.

14 Dong Z, Wang Y, Qiu Q, Zhang X, Zhang L, $\mathrm{Wu}$ J, et al. Clinical predictors differentiating non-diabetic renal diseases from diabetic nephropathy in a large population of type 2 diabetes patients. Diabetes Res Clin Pract. 2016 Nov; $121: 112-8$.

$15 \mathrm{Chu} \mathrm{H}$, Cole SR. Bivariate meta-analysis of sensitivity and specificity with sparse data: a generalized linear mixed model approach. J Clin Epidemiol. 2006 Dec;59(12): 1331-2.

16 Van Houwelingen HC, Zwinderman KH, Stijnen T. A bivariate approach to meta-analysis. Stat Med. 1993 Dec;12(24):2273-84.
17 van Houwelingen HC, Arends LR, Stijnen T Advanced methods in meta-analysis: multivariate approach and meta-regression. Stat Med. 2002 Feb;21(4):589-624.

18 Reitsma JB, Glas AS, Rutjes AW, Scholten RJ Bossuyt PM, Zwinderman AH. Bivariate analysis of sensitivity and specificity produces informative summary measures in diagnostic reviews. J Clin Epidemiol. 2005 Oct;58(10): 982-90.

19 Riley RD, Abrams KR, Sutton AJ, Lambert PC, Thompson JR. Bivariate random-effects meta-analysis and the estimation of betweenstudy correlation. BMC Med Res Methodol. 2007 Jan; 7(1):3.

20 Fagan TJ. Letter: nomogram for Bayes theorem. N Engl J Med. 1975 Jul;293(5):257.

21 Parving HH, Gall MA, Skøtt P, Jørgensen HE, Løkkegaard H, Jørgensen F, et al. Prevalence and causes of albuminuria in non-insulin-dependent diabetic patients. Kidney Int. 1992 Apr;41(4):758-62.

22 Fioretto P, Mauer M, Brocco E, Velussi M, Frigato F, Muollo B, et al. Patterns of renal injury in NIDDM patients with microalbuminuria. Diabetologia. 1996 Dec;39(12): 1569-76.

23 Olsen S, Mogensen CE. How often is NIDDM complicated with non-diabetic renal disease? An analysis of renal biopsies and the literature. Diabetologia. 1996 Dec;39(12):1638-45.

24 Brocco E, Fioretto P, Mauer M, Saller A, Carraro A, Frigato F, et al. Renal structure and function in non-insulin dependent diabetic patients with microalbuminuria. Kidney Int Suppl. 1997 Dec;63:S40-4.

25 Nzerue CM, Hewan-Lowe K, Harvey P, Mohammed D, Furlong B, Oster R. Prevalence of non-diabetic renal disease among AfricanAmerican patients with type II diabetes mellitus. Scand J Urol Nephrol. 2000 Oct;34(5): 331-5. 
26 Christensen PK, Larsen S, Horn T, Olsen S, Parving $\mathrm{HH}$. Causes of albuminuria in patients with type 2 diabetes without diabetic retinopathy. Kidney Int. 2000 Oct;58(4):1719-31.

27 Serra A, Romero R, Bayés B, Lopez D, Bonet $\mathrm{J}$. Is there a need for changes in renal biopsy criteria in proteinuria in type 2 diabetes? Diabetes Res Clin Pract. 2002 Nov;58(2):149-53.

28 Wong TY, Choi PC, Szeto CC, To KF, Tang NL, Chan AW, et al. Renal outcome in type 2 diabetic patients with or without coexisting nondiabetic nephropathies. Diabetes Care. 2002 May;25(5):900-5.

29 Li H, Li XW, Huang QY, Ye WL, Duan L, Li Y. Non-diabetic renal disease in type II diabetes mellitus. Zhongguo Yi Xue Ke Xue Yuan Xue Bao. 2003 Feb;25(1):101-4.

30 Tone A, Shikata K, Matsuda M, Usui H, Okada S, Ogawa D, et al. Clinical features of nondiabetic renal diseases in patients with type 2 diabetes. Diabetes Res Clin Pract. 2005 Sep; 69(3):237-42.

31 Zhou J, Chen X, Xie Y, Li J, Yamanaka N, Tong X. A differential diagnostic model of diabetic nephropathy and non-diabetic renal diseases. Nephrol Dial Transplant. 2008 Jun; 23(6):1940-5

32 Lin YL, Peng SJ, Ferng SH, Tzen CY, Yang CS. Clinical indicators which necessitate renal biopsy in type 2 diabetes mellitus patients with renal disease. Int J Clin Pract. 2009 Aug;63(8): 1167-76.

33 Chang TI, Park JT, Kim JK, Kim SJ, Oh HJ, Yoo DE, et al. Renal outcomes in patients with type 2 diabetes with or without coexisting non-diabetic renal disease. Diabetes Res Clin Pract. 2011 May;92(2):198-204.

34 Oh SW, Kim S, Na KY, Chae DW, Kim S, Jin DC, et al. Clinical implications of pathologic diagnosis and classification for diabetic nephropathy. Diabetes Res Clin Pract. 2012 Sep; 97(3):418-24.

35 Byun JM, Lee CH, Lee SR, Moon JY, Lee SH, Lee TW, et al. Renal outcomes and clinical course of nondiabetic renal diseases in patients with type 2 diabetes. Korean J Intern Med (Korean Assoc Intern Med). 2013 Sep; 28(5):565-72.

36 Harada K, Akai Y, Sumida K, Yoshikawa M, Takahashi H, Yamaguchi Y, et al. Significance of renal biopsy in patients with presumed diabetic nephropathy. J Diabetes Investig. 2013 Jan;4(1):88-93.

37 Jin Kim Y, Hyung Kim Y, Dae Kim K, Ryun Moon K, Ho Park J, Mi Park B, et al. Nondiabetic kidney diseases in type 2 diabetic patients. Kidney Res Clin Pract. 2013 Sep;32(3):115-20.

38 Horvatic I, Tisljar M, Kacinari P, Matesic I, Bulimbasic S, Galesic Ljubanovic D, et al. Non-diabetic renal disease in Croatian patients with type 2 diabetes mellitus. Diabetes Res Clin Pract. 2014 Jun;104(3):443-50.

39 Pallayova M, Mohammed A, Langman G, Taheri S, Dasgupta I. Predicting non-diabetic renal disease in type 2 diabetic adults: the value of glycated hemoglobin. J Diabetes Complications. 2015 Jul;29(5):718-23.
40 Soleymanian T, Hamid G, Arefi M, Najafi I, Ganji MR, Amini M, et al. Non-diabetic renal disease with or without diabetic nephropathy in type 2 diabetes: clinical predictors and outcome. Ren Fail. 2015 May;37(4):572-5.

41 Wągrowska-Danilewicz M, Danilewicz M. Spectrum of biopsy-proven renal diseases in patients with type 2 diabetes mellitus. A single center study. Pol J Pathol. 2015 Dec;66(4): 361-7.

42 Bermejo S, Soler MJ, Gimeno J, Barrios C, Rodríguez E, Mojal S, et al. Predictive factors for non-diabetic nephropathy in diabetic patients. The utility of renal biopsy. Nefrologia. 2016 Sep - Oct;36(5):535-44.

43 Lee YH, Kim KP, Kim YG, Moon JY, Jung SW, Park E, et al. Clinicopathological features of diabetic and nondiabetic renal diseases in type 2 diabetic patients with nephrotic-range proteinuria. Medicine (Baltimore). 2017 Sep; 96(36):e8047.

44 Li L, Zhang X, Li Z, Zhang R, Guo R, Yin Q, et al. Renal pathological implications in type 2 diabetes mellitus patients with renal involvement. J Diabetes Complications. 2017 Jan;31(1):114-21.

45 Tan J, Zwi LJ, Collins JF, Marshall MR, Cundy T. Presentation, pathology and prognosis of renal disease in type 2 diabetes. BMJ Open Diabetes Res Care. 2017 Aug;5(1):e000412.

$46 \mathrm{Xu}$ J, Hu XF, Huang W, Shen PY, Zhang W, Ren H, et al. The clinicopathological characteristics of diabetic nephropathy and non-diabetic renal diseases in diabetic patients. Zhonghua Nei Ke Za Zhi. 2017 Dec;56(12): 924-9.

47 Fan JZ, Wang R. Non-diabetic renal disease in patients with type 2 diabetes: a single centre study. Intern Med J. 2018 Apr;48(4):451-6.

48 Mak SK, Gwi E, Chan KW, Wong PN, Lo KY, Lee KF, et al. Clinical predictors of non-diabetic renal disease in patients with non-insulin dependent diabetes mellitus. Nephrol Dial Transplant. 1997 Dec;12(12):2588-91.

49 Lee EY, Chung CH, Choi SO. Non-diabetic renal disease in patients with non-insulin dependent diabetes mellitus. Yonsei Med J. 1999 Aug;40(4):321-6.

50 Akimoto T, Ito C, Saito O, Takahashi $\mathrm{H}$, Takeda S, Ando Y, et al. Microscopic hematuria and diabetic glomerulosclerosis-clinicopathological analysis of type 2 diabetic patients associated with overt proteinuria. Nephron Clin Pract. 2008;109(3):c119-26.

51 Pham TT, Sim JJ, Kujubu DA, Liu IL, Kumar VA. Prevalence of nondiabetic renal disease in diabetic patients. Am J Nephrol. 2007; 27(3):322-8.

52 Bi H, Chen N, Ling G, Yuan S, Huang G, Liu $R$. Nondiabetic renal disease in type 2 diabetic patients: a review of our experience in 220 cases. Ren Fail. 2011;33(1):26-30

53 Moger V, Kumar SK, Sakhuja V, Joshi K, Walker R, Kohli HS, et al. Rapidly progressive renal failure in type 2 diabetes in the tropical environment: a clinico-pathological study. Ren Fail. 2005;27(5):595-600.
54 Soni SS, Gowrishankar S, Kishan AG, Raman A. Non diabetic renal disease in type 2 diabetes mellitus. Nephrology (Carlton). 2006 Dec; 11(6):533-7.

55 Chong YB, Keng TC, Tan LP, Ng KP, Kong WY, Wong CM, et al. Clinical predictors of non-diabetic renal disease and role of renal biopsy in diabetic patients with renal involvement: a single centre review. Ren Fail. 2012; 34(3):323-8

56 Wilfred DC, Mysorekar VV, Venkataramana RS, Eshwarappa M, Subramanyan R. Nondiabetic Renal Disease in type 2 Diabetes Mellitus Patients: A Clinicopathological Study. J Lab Physicians. 2013 Jul;5(2):94-9.

57 Yenigun EC, Dede F, Ozturk R, Turgut D, Koc E, Piskinpasa SV, et al. Non-Diabetic renal disease in Diabetes Mellitus: clinical features and renal biopsy findings. Hippokratia. 2015 Apr-Jun;19(2):148-52.

58 Liu S, Guo Q, Han H, Cui P, Liu X, Miao L, et al. Clinicopathological characteristics of nondiabetic renal disease in patients with type 2 diabetes mellitus in a northeastern Chinese medical center: a retrospective analysis of 273 cases. Int Urol Nephrol. 2016 Oct;48(10): 1691-8.

59 Erdogmus S, Kiremitci S, Celebi ZK, Akturk S, Duman N, Ates K, et al. Non-diabetic kidney disease in type 2 diabetic patients: Prevalence, clinical predictors and outcomes. Kidney Blood Press Res. 2017;42(5):886-93.

60 Kanodia KV, Vanikar AV, Nigam L, Patel RD, Suthar KS, Patel H. Clinicopathological study of nondiabetic renal disease in type 2 diabetic patients: A single center experience from India. Saudi J Kidney Dis Transpl. 2017 NovDec;28(6):1330-7.

61 Mami I, Harzallah A, Kaaroud H, Aoudia R, Hamida FB, Goucha R, et al. Nondiabetic renal disease in patients with type 2 diabetes. Saudi J Kidney Dis Transpl. 2017 Jul-Aug; 28(4):842-50.

62 John GT, Date A, Korula A, Jeyaseelan L, Shastry JC, Jacob CK. Nondiabetic renal disease in noninsulin-dependent diabetics in a south Indian Hospital. Nephron. 1994;67(4): 441-3.

63 Deeks JJ. Systematic reviews in health care: systematic reviews of evaluations of diagnostic and screening tests. BMJ. 2001 Jul; 323(7305): 157-62.

64 Li J, Dong Y, Wu T, Tong N. Differences between Western and Asian type 2 diabetes patients in the incidence of vascular complications and mortality: A systematic review of randomized controlled trials on lowering blood glucose. J Diabetes. 2016 Nov;8(6):82433.

65 Stolk RP, van Schooneveld MJ, Cruickshank JK, Hughes AD, Stanton A, Lu J, et al.; AdRem Project Team and ADVANCE Management Committee. Retinal vascular lesions in patients of Caucasian and Asian origin with type 2 diabetes: baseline results from the $\mathrm{AD}$ VANCE Retinal Measurements (AdRem) study. Diabetes Care. 2008 Apr;31(4):708-13. 